\title{
Teacher Educators under Surveillance at a Religious University
}

Genevieve Harris

Linfield College

Follow this and additional works at: https://digitalcommons.linfield.edu/educfac_pubs

Part of the Teacher Education and Professional Development Commons

\section{DigitalCommons@Linfield Citation}

Harris, Genevieve, "Teacher Educators under Surveillance at a Religious University" (2011). Faculty Publications. Accepted Version. Submission 6.

https://digitalcommons.linfield.edu/educfac_pubs/6

This Accepted Version is protected by copyright and/or related rights. It is brought to you for free via open access, courtesy of DigitalCommons@Linfield, with permission from the rights-holder(s). Your use of this Accepted Version must comply with the Terms of Use for material posted in DigitalCommons@Linfield, or with other stated terms (such as a Creative Commons license) indicated in the record and/or on the work itself. For more information, or if you have questions about permitted uses, please contact digitalcommons@linfield.edu. 


\title{
Teacher educators under surveillance at a religious university
}

\author{
Genevieve Harris
}

Education Department, Linfield College, McMinnville, Oregon, USA

Genevieve Harris, PhD

Assistant Professor of Multicultural Education

Linfield College

Education Department

900 SE Baker St. \#A474

McMinnville, OR 97128

USA

Phone: 1-503-883-2238

Fax: 1-503-883-2686

geharris@linfield.edu

\begin{abstract}
:
The purpose of this paper is to examine how institutional norms are enforced through surveillance and selfdiscipline among teacher educators at a religious university. The study builds on prior research regarding university norms and surveillance, as well as religious orientation and prejudice. Eight teacher educators met as part of a larger study on white racial identity and praxis. Focus groups and personal interviews were transcribed and analyzed using situational mapping, a postmodern form of grounded theory. Participants discussed four themes that illustrate surveillance and self-discipline: the university, academic culture, religion \& whiteness, and sexism. The data reveal participant responses as highly structured by university norms about what one can and cannot say about particular topics. The results confirm the function of surveillance and norms in a university setting and illuminate the process in a religious context. Data reveal how fear played a part of the process, as participants disciplined themselves to fit university norms and censored themselves when they began to exercise agency.
\end{abstract}

Key Words: teacher education; teacher characteristics; organizational culture; academic discourse; role of religion 


\section{Teacher educators under surveillance at a religious university}

This research highlights the surveillance of institutional norms among eight teacher educators who participated in a qualitative research study within a religious university. Participant contributions appeared to be highly structured by university norms about appropriate discourses and emotional responses, what one can and cannot say—feel or not feel—about particular topics. Surveillance within higher education settings has been widely studied, but not within religious settings and not specifically with regard to teacher educators.

The university in which this study was conducted maintains membership within the Council for Christian Colleges and Universities (CCCU), whose mission is to "advance the cause of Christ-centered higher education and to help [its] institutions transform lives by faithfully relating scholarship and service to biblical truth" (http://www.cccu.org). One hundred and nine institutions within the United States, as well as 75 "affiliate" institutions globally, have met the necessary criteria to qualify as members of the CCCU. Beyond the CCCU, 900 of the 1600 private university campuses in the United States are religiously affiliated. Teacher education exists within religious universities worldwide.

As part of preparing teachers for diverse students, it is common to study race and whiteness in teacher education. But the norms of academia, local contexts, and belief systems play a profound role in how preservice teachers are educated, in what can be taught or not taught within institutions, and in how teacher educators participate as faculty members. The purpose of this paper is to examine how institutional norms are enforced through surveillance within a religious - in this case evangelical Christian — setting. Specifically, the guiding research question was: How does location within a religious university impact how white Christian teacher educators tell stories about their racial identity development? 


\section{Literature review}

Quantitative research studies have shown a correlation among certain religious beliefs and prejudice (Allport \& Ross, 1967; Altemeyer \& Hunsberger, 1992; Kirkpatrick, 1993; McFarland, 1989). Sciarra and Gushue (2003) found that participants with higher levels of white racial identity development held more "personally integrated and flexible forms of religious orientation" (p. 479), while those with rigid beliefs possessed lower levels of white racial identity development.

Several studies have examined surveillance and academic normalizing within higher education settings. Brenner (2006) researched the broad effects of changes in higher education in the United States such as the corporatizing of higher education structure, the elimination of tenure-track positions, and increased reliance on course evaluations related to job security; such evaluations lead to the surveillance of norms, especially over faculty on year-to-year contracts. Broadhead and Howard (1998) examined the effects of assessment in education on academics in Great Britain. They discovered that the Research Assessment Exercise (RAE), which assesses faculty publications and ties results to funding, served a disciplinary function on academics and had negative impacts on teaching and learning. Devos (2004) found that female faculty members, who generally possess lower rank and are more likely to be on year-to-year contracts, are particularly vulnerable to the effects of university surveillance. Chan (2005) and Huckaby (2007) explored the academic normalizing processes at universities. Chan discovered disconnects between policy discourses of diversity and actual practice, while Huckaby examined scholars who disrupt the status quo. These studies provide useful insights into how surveillance operates in higher education, but none of them specifically examined surveillance within a religious institution. 
The above studies utilize Foucauldian principles of disciplinary power in conjunction with surveillance. Siebert and Mills (2007) explain Foucault's (1991) metaphor of the Panopticon in a prison setting. The Panopticon is an arrangement of buildings with a tower in the center surrounded by cells that face the tower and are completely observable from the tower at all times. As a result "the subjects of surveillance are forced to discipline themselves, and even if the guardian is not present, the inmates still feel observed" (Siebert \& Mills, 2007, p. 310) and police their own behavior. In Foucault's conception, power is not something that only authorities possess. Rather, power is dynamic, shifting and in constant negotiation. Foucault would shift the focus from who has power to how is power used and maintained? (St. Pierre, 2000). In the university settings described above, power is maintained by various normalizing practices, such as course evaluations, institutional policies, and even the "hegemony of academic methodology" (Siebert \& Mills, 2007, p. 315). Because surveillance is ever-present, academics are conditioned to police themselves to ensure they are meeting institutional norms.

Multiple Foucauldian terms are used by researchers as descriptors for the phenomenon of the surveillance of university norms. I have adopted Siebert and Mills' (2007) use of the terms surveillance and self-discipline. Disciplinary power "signifies those processes that enable an institution to gain knowledge about its people in order to manage them effectively" (p. 310), or to maintain surveillance on them. Self-discipline refers to the individual's "confessional practices" (p. 310) of remaining aligned with institutional norms. Poststructuralists have long used Foucauldian principles as a means of deconstructing taken-for-granted assumptions about the world (St. Pierre, 2000), and poststructuralism provides helpful language for describing the nuances of examining surveillance and self-discipline within a religious university. 
Discourse is a foundational concept in poststructuralism. "Discourses are frameworks for thought and action that groups of individuals draw upon in order to speak and interact with one another in meaningful ways" (Marsh, 2002, p. 456). Discourses are far more than just words: they are ways of thinking that are deemed to be socially acceptable and meaningful within a particular context. Within religious institutions, certain ways of speaking, thinking, and being in the world are acceptable while others are not.

Based on the concept of discourse, the self is not merely an individual but is also socially and politically constructed (Zembylas, 2003) - a critical distinction in the poststructural definition of identity and one that allows a complex examination of the self within a religious setting. Winograd (2005) and Zembylas (2003) suggest that emotions are a critical element of identity. Zembylas states "families, cultures, and school situations ... profoundly influence how and when particular emotions are constructed, expressed, and communicated" (p. 216). Dysfunctional emotional labor exists when there is a "large and persistent gap between reality and the impressions one is projecting to others" (Winograd, p. 263). Impression management serves as a way to present oneself as meeting institutional norms.

The subject is given special consideration in poststructuralism, and two concepts, subjectivity and agency, are important and related. The subject is dynamic and ever changing, not just over time but also from situation to situation, as varying discourses are required. As these discourses influence a person's subjectivity, new configurations of identity are possible (Zembylas, 2003). Agency is how individuals work through discourses to recreate themselves, to find fissures in powerful dominant discourses, and to make sense of themselves within different discourses. Poststructuralism allows movement beyond “absolutes and deep structures" (p. 484), 
such as religious doctrine, to a place where all subjects are responsible for - and should take action to improve- the state of our institutions.

Because this study focused on how white Christian teacher educators talked about their own racial identity development, discourses of whiteness must be considered. According to Owen (2007), whiteness structures institutions within the United States and serves as a "set of presuppositions that underlie the functioning of the economic, political, legal, and other systems" (p. 212). To complicate matters, within the discourse of academia, discussing messy, controversial topics is considered inappropriate (Thompson, 2004). Thompson elaborates, “oppression is, after all, ugly and inelegant, it is hard to talk about sexism, racism, classism, homophobia, xenophobia, and ethnocentrism without getting messy" (p. 51). Going beyond the complex social structure of academia, the purpose of this study is to examine how surveillance and self-discipline operate during a study on whiteness at a religious university.

\section{Research context}

During the time of the research, 3,253 students (60\% undergraduate and $40 \%$ graduate) were enrolled at the university, which is located in the Pacific Northwest in the United States. The largest denomination represented among undergraduates was Baptist. The university does have a documented plan for achieving diversity, but like many private institutions in the region, the student and faculty populations are overwhelmingly white; $80 \%$ of undergraduates were white, while statistics for graduate students and faculty were unavailable.

The mission of the university is explicitly evangelical. Torode (2005) defines three common traits of evangelical Christians: a belief in salvation through faith in Christ, the need for each person to have a personal relationship with Jesus, and that the Bible as the guide for doctrine and daily life. These norms were in place at the university and were clearly outlined in 
the institution's statement of beliefs. All faculty members signed a document indicating their willingness to follow university beliefs, including specific "lifestyle standards" regarding excessive drinking, gambling, sex outside of marriage, pornography, and homosexuality. Faculty members who did not follow the rules could be terminated.

The eight participants in this study were full-time faculty in a graduate-level teacher licensure program. They signed a required document indicating evangelical faith and an agreement to follow the university lifestyle standards. Participants were recruited from among nineteen members of a teacher education department, just two of whom were faculty of color. I assigned pseudonyms to participants and to other faculty members mentioned by participants. More specific descriptions are provided in Table 1.

\section{(Insert Table 1)}

As the researcher, I am a white, female teacher educator and was a member of the department when the study began. As an employee of the institution, I signed the university lifestyle statement and operated within the university norms. I felt the gaze of surveillance and threat of termination. Midway through the research process I applied for—and accepted —a position at a different institution.

Being a colleague proved helpful in understanding the evangelical culture (Siebert \& Mills, 2007), but also challenging, as I felt at times too close to participants and to the context. Because of this, I wrote detailed research memos over a six-month period, creating an audit trail (Gall, Gall, \& Borg, 2005) of the data collection and data analysis processes. Five distant colleagues agreed to review my research memos and compare them to my analysis. 


\section{Methods and ongoing data analysis}

This research was part of a larger qualitative study focused on whiteness, race, and praxis among Christian teacher educators. Given my research questions, I sought to employ qualitative research, and I anticipated that participants would discuss issues of whiteness and how it may impact their praxis. Indeed, they did so extensively. However, they also addressed themes that I did not anticipate, themes about the university, academic culture, religion and whiteness, and sexism. The purpose of this paper is to illuminate the latter themes in light of institutional norms and surveillance.

Several department members discussed a desire to read Tatum's (1999) Why are all the Black Kids Sitting Together in the Cafeteria? And Other Conversations About Race. This study provided an opportunity to read and discuss the book. Participants met during three 90-minute focus groups to participate in structured discussions about the readings. Focus group discussions addressed topics in the reading, personal memories about race, and the meaning of being a white teacher educator in a predominantly white context. Each participant took part in an individual 60-minute interview at the end of the study. The purpose of the interviews was to revisit the topics discussed in the focus groups, as well as a final question, Has your participation in this study affected your praxis? If so, how? If not, why not? How might it affect your praxis in the future? The focus groups and interviews were transcribed. Field notes (Tjora, 2006) provided additional data, and research memos (Clarke, 2005) informed the data analysis process.

Situational mapping (Clarke, 2005), a postmodern form of grounded theory, served as the ongoing data analysis procedure. Situational maps "lay out the major human, nonhuman, discursive, and other elements in the research situation of inquiry and provoke analysis of relations among them" (Clarke, p. xxii). Working version maps were generated at the beginning 
of the inquiry and revised throughout the entire research process. Throughout the creation of the working maps, relationships among discourses/elements were analyzed and connections were indicated through dotted lines, arrows, and words. Each mapping session generated memos, as well as questions and suggestions for next steps. By the end of the working version process, various conclusions in memos led to relative ease in converting the working maps into an ordered map, which represented combined focus group and interview data. Then, the discourses were organized into themes. The ordered map was modified until a saturation point was reached. Clarke describes saturation as a time when the data have been analyzed over a period of time and all relevant themes seem to have emerged. Triangulation (Creswell, 2005) was achieved by the use of multiple sources of data: interviews for individual perspectives, focus groups for collaboratively-constructed understandings, and field notes and memos to examine my own understandings of the research content and process.

\section{Results}

Four themes, the university, academic culture, religion and whiteness, and sexism, are presented in this article and illuminate how the surveillance of norms and self-discipline functioned at the university. Five participants discussed these issues openly; the other participants did not address these controversial topics.

\section{University}

University refers to the institution where the research took place, and this section refers to participants' experiences within different parts of the organization. Participants displayed a carefulness about their words throughout the study and, on occasion, self-censorship while speaking. Two participants described their self-censorship about race. 
Debbie contributed to a university-wide committee during the time of the study, about which she said, it "made me question my own sense of courage and my own sense of integrity." She could not discuss specific elements about the committee work, but said that overall, I think I could say that it gave me great insight into how many broken places really exist in my university. And I love our university. I really do. I have loved working here. I love the people I work with. That committee exposed me to a broader range of folks that all serve the same common goal, and it let me know that issues of gender and race are annoying to many people, and I hadn't anticipated that.

Debbie went on to discuss the experience on the committee in terms of a system, describing her resulting decision to attend a multicultural church, "And so I went thinking I am frustrated with the system. I need to [help people], and I came away thinking, no, I am frustrated with the system, and I need a group of people to [help] me."

Debbie discussed the implications of working in a white academic institution. She said that she began attending a multicultural church with her husband "because we feel impoverished, linguistically and spiritually and intellectually [within a white system]. In a way, I believe that to be a white teacher in a white context, if we are not actively working towards change, then I think it may be intellectually dishonest." In connecting to the wider institution, she said,

Because if I tell you that I believe in learning and that I believe in searching for broader and ever-widening understandings, then to continue in a completely white context means that I am not really serious about that search. In the same way in which, if we look at a university ... I am going to get off on a soapbox, and I'm sorry.

Leanne implied that the university may not be a safe place to discuss racial issues. She said that she felt comfortable in the focus groups, stating, "I think that we have such a unique department, and certainly the people who chose to participate in the study chose, I'm assuming, because they have an interest in the topic or a passion or desire to learn more." As a result, she 
felt it was a safe place, and she said that "even within [the wider education department] I feel like it would be a safe place to have some of these discussions." Then she added, "As I learned more about the broader university here ..." and stopped talking.

Conservative politics were addressed by one participant in reference to the university. Conservative political ideals seemed to be part of the authoritative discourse of the institution. Debbie stated,

But if we look at a university that is a Christian university, and we say everyone must attend to certain belief systems, and in the evangelical world, they tend towards conservative belief systems, then I don't think we are being particularly intellectually honest. Because if we really want to know who God is in the world at large, then we have to open the gates and go out through them and start saying, "Where else would we find Jesus in the midst of all this?" It is not in a confined place of thinking or believing or voting.

Debbie concluded this statement by saying, "I'm sorry."

\section{Academic culture}

Academics are expected to be experts, to be sure of themselves and of the "facts" or "truth" regarding any given topic within one's field of expertise. Ellen and Eric explicitly discussed issues of academic culture and norms with regard to diversity.

Ellen expressed a sense of vulnerability in self-disclosing within the academic culture.

She said, about her interest in racial issues,

Sometimes knowledge is scary because it points out ignorance, and ignorance is embarrassing. And for people who are educated and who are the professor in the situation, we like to be knowledgeable and understanding. It is embarrassing to find yourself in a situation where you think, "Oh my gosh, where did that thinking come from?" 
Despite these fears, she said, "I think these conversations are good conversations that we need to have, and so I think it has been a profitable thing for everybody to do despite the risks and fears, so I think we need to have more of this."

Ellen elaborated about the norms of academia:

In the educational environment, the values are having it all together, having the right answer and the perfect answer. We oftentimes don't know how to handle it, and if we come out with [an answer] that is different from the rest or if we are going to say all that for the first time, we have to really examine, "Now how do I, not only deal with myself and who I am and how I believe, but do I handle others' perception of who I am based on that? And what are my expectations of others, and is there a safe environment to work this out?" Eric discussed university course evaluations and white privilege in academia. During the time of the study, the university was piloting and receiving faculty feedback about new course evaluations. In the personal interview, he discussed how they might be biased against women, non-native English speakers, and others who do not fit the academic norm. For example, the evaluations asked if the instructors used Standard English, spoke loudly, and made eye contact with students. In order to present concerns about the course evaluation, Eric said he would tell the person in charge that it "may lack construct validity. Our construct is good teaching, and by limiting what that looks like, we are going to get false negatives. You know what I'm saying?' I replied, "You need to speak the language people will hear," and he said, "Yeah, because ultimately that is what it is." He elaborated, "There are places [in academia] where you are going to get listened to ... There are places where you will get listened to later on, if you can get it on hold." He added,

But in a faculty meeting there is going to be a certain status thing going on, even to the point that if I try to pull some of that stat[istics] language it is going to sound better, because that is a privileged thing. 
Eric discussed how he might be able to use the norms of academia, in this case the value of statistics, in order to create change.

\section{Religion and whiteness}

Because of the setting in an evangelical university, participants referred to evangelical belief systems as related to race. The contributions included here are those that directly addressed norms that exist and are enforced within evangelical settings.

Ellen said, oftentimes in light of an orthodox church, "other" is seen as, they wouldn't say less than, but needy, maybe is the word for it. So we go to minister to those "other" people that don't quite have the privilege we have. Debbie linked white privilege to sexism, saying, "It means a certain level of privilege. Because I am gender deficient, and ... in the evangelical world, female is gender deficient ... there is an understanding on some level of what it must be. But I belong to the privileged class." Debbie went on to describe the privileges that she has being white, such as possessing the dominant language and knowing how to navigate systems of power, including education.

Debbie also described two race-related events in her life in terms of evangelical theology. First, she talked about how her father was a "good evangelical" and did not protest the Vietnam War. He was also a supporter of the Civil Rights Movement, yet he did not want his daughter dating an African-American. He said, "Babe, I know that there is nothing wrong before God with interracial couples, but you would be working so uphill all the days of your life, that I don't know if I could bear to watch it.” Debbie added,

This is the same man who immediately, the second it was on film and available, was showing Guess Who's Coming to Dinner? to his high school classes. You could tell that intellectually he was in one place and emotionally he was in another and that is heart had not caught up to his head. 
Debbie also described going to a conservative Baptist college as an undergraduate in the 1980s and what that experience was like in terms of race. She said,

The whites were with the whites, and the Hispanics were with the Hispanics, and the foreigners were with the foreigners. I don't think we allowed black students. I'm sure they allowed them because we got federal money, but I don't remember African-Americans being there at all. But I do remember it was a very hierarchal life and as woman I certainly knew that.

Debbie acknowledged that "foreigner" is not currently an acceptable term but one that was used during that time period, within that context.

\section{Sexism}

Discussion of gender issues occurred quite frequently in the study; female and male participants alike contributed to the data in this theme.

Jim talked about how because of the university's history, it is difficult to bring faculty and students from "different races or cultures or ethnicities" to campus. He related this to women at the university, saying, "When I first came to [the university] ... you found very, very, very, very few women who were professors on campus." Jim found this situation puzzling, particularly since the university claims to value gender equity.

Eric explored his gender identity as a male teacher educator. He said, "I don’t always fit the image of teacher. Now I do as a physics teacher. I don't as a teacher educator." He explained, “Because I'm supposed to wear a denim jumper. Or I'm supposed to be more like Jim or Ben.”

Debbie brought up gender in relation to her experience attending an evangelical college and then related these experiences to her present life as a professor at an evangelical university. Regarding her own undergraduate experience, she said, 
I learned that there were certain ways of speaking that would always be honored and respected and would further the conversation. I learned that those ways often required that I put on a certain nice lady outfit, not physically but mentally, and engaged in verbiage that other people could hear.

Relating this to her life today, she said, "And I am going to be [age] in two months, and I continue to struggle with whether or not that kind of verbiage is a violation of who I am or whether or not it simply is a bridge that allows people to cross over and take a peek at something else." Debbie struggles with her identity within the context of evangelical life.

She went on to provide a rich metaphor for her experience at the Baptist college, saying,

Years later, I would come in contact with a middle school kid who was doing a study on a brank. They used to put an iron cage over a woman's head with a piece that went into her mouth that kept her tongue down. In Middle Age homes there were actually branking posts next to the fireplace, so a husband could call the sheriff and have his wife branked to keep her in line, and I often thought that so much of what I learned in that place was teaching one how to wear the brank gracefully. As a student, that is what I learned. Oh, joy.

Debbie's lifelong affiliation with evangelical culture has provided her with many opportunities to consider sexism.

\section{Discussion}

Institutional norms profoundly influence what it means to be a teacher educator, and in the case of this evangelical university, what it means to be a "good Christian." Participants discussed issues of the university, academia, religion and whiteness, and sexism while under the gaze of surveillance and while participating in self-discipline. To question the norms may seem inappropriate, political (Huckaby, 2007), and even un-Christian, no minor infraction in a context in which violating a statement of faith may result in termination. Debbie's and Leanne's self- 
censorship serve as the best example of this, but one must wonder what else participants did not say as a result of surveillance.

Within the broader university, Debbie encountered a system that she perceived as monocultural and disinterested in matters of gender and race. Chan (2005) cites the power of dominant ideologies in maintaining institutional norms, and Debbie felt frustrated when encountering them. The deep presuppositions (Owen, 2007), or norms, seem natural to most, and individuals who think otherwise are left to discipline themselves. In some ways, this study provided an opportunity for participants to exercise agency, in speaking out against norms (Chan, 2005), but more often than not participants exercised self-discipline that suppressed this desire. Huckaby (2007) states of scholars, "Both supporting and challenging current states of power relations are political acts. Within the confines of our social constructions, however, countering and challenging acts are deemed political, while supporting, maintaining and sustaining are seen as neutral" (p. 522). Debbie and Leanne rightly sensed danger in divulging too much information that would run counter to university norms and of being seen as "too political." It is also likely that as lower-level academics, who are more often than not women, they may have felt more constrained by university norms than those with higher rank (Devos, 2004).

Because of norms of academia (Thompson, 2004) Ellen felt uncomfortable revealing any ignorance she may have about race within the academic setting. Eric less directly addressed the culture of academia when talking about course evaluations. He suggested that the proper approach would be to criticize the construct validity of the course evaluations, as opposed to talking about issues of race, language, and gender. This is an illustration of how whiteness provides cognitive and evaluative frameworks around the norm (Owen, 2007). Chan (2005) 
explains that there are professional expectations of collegial behavior that must be followed within academia. Course evaluations themselves serve a normalizing and surveillance function (Brenner, 2006). In the case of the course evaluations that Eric described, it seems they would serve as a way to determine who "fits in" in academia, as constructed by whiteness and patriarchy. The "good" professor, according to the course evaluations would speak loudly, use Standard English, and make direct eye contact, all of which privilege white male professors who are native English speakers.

Religious institutions are not immune from being structured around whiteness (Owen, 2007). As illustrated by Debbie's father, being a "good evangelical" may mean contradictory things, such as not protesting a war and yet voting for the Civil Rights Movement. A disconnect may exist between one's feelings about justice and equity and one's actions. Ellen discussed a prevailing view in white evangelical churches that the "other," or those who are not white, are seen as needy and as those who should be ministered to. People of color were objects of statements, not legitimate subjects with agency (St. Pierre, 2000). It is interesting to consider Ellen's statement in light of St. Pierre (2000), who wrote, "the rules of discourse allow certain people to be subjects of statements and others to be objects. Who gets to speak? Who is spoken?" (p. 485). People of color are often spoken about in white evangelical discourse. Similarly, women are often viewed as objects, as Debbie's contributions illustrate. They are to play a secondary role and are not viewed as legitimate subjects with agency.

University diversity statements, which include gender equity, are not necessarily lived out when other norms dominate university life. Jim's struggle with the low number of female faculty upon entering the institution illustrates how hiring practices within institutions often serve to maintain norms in that those hired may mirror current faculty (Chan, 2005). As a male 
faculty member in a predominantly female department, Eric explored his identity as a male teacher educator versus his identity as a physics professor. His awareness of these norms is particularly important within an institution in which student course evaluations have much influence over tenure and promotion decisions (Brenner, 2006). Not looking or acting like a "good" teacher educator (i.e. nurturing, feminine) could result in low course evaluations. An emerging body of research regarding emotions and teaching exists (Winograd, 2005; Zembylas, 2003), and this literature connects well with participant fears about breaking academic norms. Zembylas (2003) asserts, “Clearly, the school organizational structure shapes teachers' perceptions of emotional propriety, of what ought to be felt in pre-defined classroom settings" (p. 225). Ellen seems acutely aware of the discourses of academia and feels fearful of violating them. Debbie and Leanne also display fear as they censor themselves when they begin to speak out against university norms. Fear operates within the framework of surveillance and discipline: it is a useful emotion for promoting the status quo and for encouraging faculty members to discipline themselves.

Debbie began to exercise agency in addressing prevailing university norms, showing frustration and hints of anger, and then disciplined herself. Winograd (2005) states that there are certain "rules for emotion [that] inhibit the free expression of emotion, particularly anger expressions that might be aimed at hierarchical/patriarchal structural arrangements or at larger economic and political structures" (p. 200). It may be surmised that Debbie has been socialized as an evangelical woman to keep that anger and frustration inside. Debbie struggles with her identity within the context of evangelical life. She faces "socio-ideological contradictions" (Winograd, 2005, p. 233) as she confronts competing discourses about equity and gender expectations. Dominant ideologies (Chan, 2005) hold sway over institutional norms: the female 
as "less than" discourse remains prevalent in the institution.

Debbie's experiences at evangelical institutions, from her own undergraduate days to her current role as a teacher educator, have been marked by sexism. She has keenly felt the gaze of surveillance and the expectation of a performance towards gendered norms (Brenner, 2006), and she has learned how to discipline herself in order to be an "acceptable" Christian woman. Debbie questions this role, even as she conforms to it. St. Pierre (2000) writes,

Once these questions can be asked of the specific, local, everyday situations that oppress women, and once the working of patriarchy is made intelligible at the level of micropractice, women can begin to make different statements about their lives. Once they can locate and name the discourses and practices of patriarchy, they can begin to refuse them. (p. 486)

This has powerful implications in the life of Debbie. She seems to be in a place of naming discourses of oppression, recognizing the effects on her life, and deciding what (if anything) to do about it. She has the potential to act out her agency and resistance to norms (Chan, 2006), yet simply leaving the institution is not always possible (Siebert \& Mills, 2007). Debbie faces the complex task of working out her identity while under surveillance, which has the real risk of job loss. While Debbie seems adept at wearing a mental "nice lady outfit," she likely faces the dysfunctional emotional labor that results "when the expectation of a particular emotion display cannot happen because of a structural constraint ... and when the worker simply does not feel the emotions that the situation requires to be displayed" (Winograd, 2005, p. 207). At what personal cost does Debbie continue to work in this environment?

\section{Conclusions}

Because large numbers of teacher education programs continue to operate within religious institutions worldwide, it is imperative to consider how the surveillance of norms affects teacher 
educators. It is also valuable to consider how "resistance and freedom are daily, ongoing practices" (St. Pierre, 2000, p. 493), providing hope within even the most oppressive circumstances.

In the state where this research occurred, teachers are charged by the accrediting organization to affirm the dignity and worth of all students. How can teacher educators develop this disposition in teacher candidates when their own dignity and worth is in question within the religious institutions for which they work? In a place highly constrained by whiteness and heterosexism, encouraging future teachers to promote equity when it comes to race and gender is particularly challenging. Further, the issue of homophobia was not discussed at all within this study, which is not surprising. The predominant norms of the institution are conservative, and thus are more likely to reflect certain prejudices, including homophobia. Discussing certain social justice issues within many religious institutions simply remains unsafe for faculty members. Teacher educators in these settings face the awkward task of preparing future teachers to work in a diverse world while censoring themselves as academics.

This research reveals how surveillance and self-discipline operate within a religious university and its effects on teacher education faculty members. Poststructuralism provided language regarding the complex, interwoven issues of discourse, identity, subjectivity, and agency; these may be useful considerations in future research on the surveillance of university norms and self-discipline and may highlight fissures within university settings, places where change might occur.

This study found that participants carefully chose what to say—or not say—as they discussed race and racial identity development and as they pondered what it means to be a white teacher educator in a predominantly white context. It was evident throughout the study that they 
disciplined themselves to meet institutional norms. Because whiteness may serve as an unspoken norm, there was uncertainty among participants in general when discussing race, and this appeared to be particularly keen within the academic context in which certainty is valued. Debbie and Leanne seemed particularly tentative as they discussed issues that university leaders may have found inappropriate or controversial, perhaps reflecting their lack of status as women in academia and evangelical culture. Their hesitations and self-censorship are bound to affect their work in preparing teachers for the diverse students of today's classrooms. Against these odds, "the potential of discursive resistance" (Huckaby, 2007, p. 517) exists in any institution. As illustrated by Debbie, teacher educators may deconstruct norms and speak and act in new ways; however, an emotional cost may be the result.

Word count: 5949 
Teacher educators under surveillance 22

\begin{tabular}{|l|l|l|l|l|}
\hline Name & Gender & Rank & Tenure Track? & $\begin{array}{l}\text { Years at } \\
\text { University }\end{array}$ \\
\hline Anne & F & Assistant & No & $5+$ \\
\hline Debbie & F & Assistant & No & $5+$ \\
\hline Ellen & F & Assistant & Yes & $5+$ \\
\hline Eric & M & Full & Yes (tenured) & $5+$ \\
\hline Jim & M & Full & Yes (tenured) & $15+$ \\
\hline Leanne & F & Assistant & No & $5+$ \\
\hline Melissa & F & Assistant & Yes & $1+$ \\
\hline Ruth & F & Assistant & No & $1+$ \\
\hline
\end{tabular}

Table 1 


\section{References}

Allport, G.W. \& Ross, J.M. (1967). Personal religious orientation and prejudice. Journal of Personality and Social Psychology, 5(4), 432-443.

Altemeyer, B. \& Hunsberger, B. (1992). Authoritarianism, religious fundamentalism, quest, and prejudice. The International Journal for the Psychology of Religion, 2(2), 113-133.

Brenner, D. (2006). Performative pedagogy: Resignifying teaching in the corporatized university. The Review of Education, Pedagogy, and Cultural Studies, 28, 3-24.

Chan, A.S. (2005). Policy discourses and changing practice: Diversity and the university-college. Higher Education, 50, 129-157.

Clarke, A.E. (2005). Situational analysis: Grounded theory after the postmodern turn. Thousand Oaks, CA: Sage.

Creswell, J.W. (2005). Educational research: Planning, conducting, and evaluating quantitative and qualitative research ( $2^{\text {nd }}$ ed.). Upper Saddle River, NJ: Pearson.

Devos, A. (2004). Women, research and the politics of professional development. Studies in Higher Education, 29(5), 591-604.

Foucault, M. (1991). Discipline and punish: The birth of the prison. London: Penguin Books.

Gall, J.P., Gall, M.D., \& Borg, W.R. (2005). Applying educational research: A practical guide ( $5^{\text {th }}$ ed.). Boston: Pearson Education.

Huckaby, M.F. (2007). A conversation on practices of the self within relations of power: For scholars who speak dangerous truths. International Journal of Qualitative Studies in Education, 20(5), 513-529.

Kirkpatrick, L.A. (1993). Fundamentalism, Christian orthodoxy, and intrinsic religious 
orientation as predictors of discriminatory attitudes. Journal for the Scientific Study of Religion, 32(3), 256-268.

Marsh, M.M. (2002). Examining the discourses that shape our teacher identities. Curriculum Inquiry, 32(4), 453-469.

McFarland, S.G. (1989). Religious orientations and the targets of discrimination. Journal for the Scientific Study of Religion, 28(3), 324-336.

McWhorter, L. (2005). Where do white people come from? A Foucaultian critique of Whiteness studies. Philosophy \& Social Criticism, 31(5-6), 533-556.

Owen, D.S. (2007). Towards a critical theory of whiteness. Philosophy \& Social Criticism, 33(2), 203-222.

Sciarra, D.T. \& Gushue, G.V. (2003). White racial identity development and religious orientation. Journal of Counseling \& Development, 81(4), 473-482.

Siebert, S. \& Mills, V. (2007). The quest for autonomy: A Foucauldian perspective on workbased research. Research in Post-Compulsory Education, 12(3), 309-317.

St. Pierre, E.A. (2000). Poststructural feminism in education: An overview. Qualitative Studies in Education, 13(5), 477-515.

Tatum, B.D. (1999). Why are all the Black kids sitting together in the cafeteria? And other conversations about race. New York: Basic Books.

Thompson, A. (2004). Gentlemanly orthodoxy: Critical race feminism, whiteness theory, and the APA manual. Educational Theory, 54(1), 27-57.

Tjora, A.H. (2006). Writing small discoveries: An exploration of fresh observers' observations. Qualitative Research, 6(4), 429-451. 
Torode, S. (2005, August). It's all about Jesus: A convert to orthodoxy reconsiders evangelicalism. Christianity Today, 49, 42-44.

Winograd, K. (2005). Good day, bad day: Teaching as a high-wire act. Lanham, MD: Scarecrow Education.

Zembylas, M. (2003). Emotions and teacher identity: A poststructural perspective. Teachers and Teaching: Theory and Practice, 9(3), 213-238. 